\title{
AUGMENTED REALITY AND VIRTUAL REALITY TECHNOLOGIES IN PROJECT MANAGEMENT: WHAT CAN WE EXPECT?
}

\author{
Zorica A. Dodevska ${ }^{1}$, Marko M. Mihić ${ }^{2}$ \\ ${ }^{1}$ Research and Development Institute Lola Ltd, Serbia \\ ${ }^{2}$ Faculty of Organizational Sciences, University of Belgrade, Serbia
}

\begin{abstract}
Whether augmented reality and virtual reality technologies could change the flow of project management in the future? The aim of this paper is to consider implementation of these raising technologies in the field of project management. It is important to answer why they are unavoidable in the future, how their usage would affect many future projects, the way of management of such projects, and the education process of the project management experts. A SWOT analysis will be presented to help to answer these questions. As disruptive technologies, they bring plenty of new opportunities and benefits. However, this is still an insufficiently explored field, so the authors want to stress the significance of augmented reality and virtual reality technologies for future development of project management practice.
\end{abstract}

Key words: Augmented reality, project management, technologies, virtual reality.

\section{INTRODUCTION}

Augmented reality (AR) and virtual reality (VR), as disruptive technologies, become increasingly present in the business environment. Their rapid expansion tends to affect various markets, industries, and related projects. Moreover, they will transform workplaces and the way how we work (Kugler, 2017). Because of unavoidable and emerging changes, project management (PM) practice need to adopt them. Despite this challenge, there are a lot of benefits from AR/VR implementation in PM which will be also considered in this paper.

As a consequence of the practical needs in PM, it is necessary to consider the education of the PM experts. However, a thorough analysis of this subject is by far beyond the scope of this paper. Therefore, only some notices about the impact of AR/VR technologies usage in PM on the education of PM experts will be considered here.

The aim of this paper is to introduce AR/VR in PM through giving answers and presenting a SWOT analysis related to implementation of these technologies in PM. In general, this paper encourages project managers to use $A R / V R$ in practice.

\section{EXPLANATION OF TERMINOLOGY RELATED TO AR/VR}

There is a terminology confusion regarding 'different realities' in the literature, as this area is still developing. At the beginning, we will clarify most commonly accepted terms related to using various kinds of virtual technologies, that are based on the Milgram's RealityVirtuality continuum, which is shown in Figure 1.

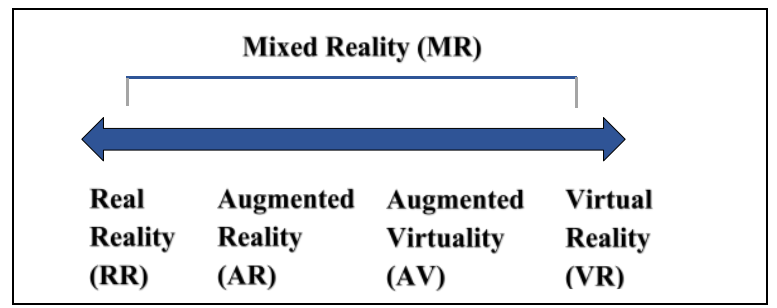

Figure 1: Milgram's Reality-Virtuality continuum (Milgram, Takemura, Utsumi, \& Kishino, 1994)

Corresponding author. Email: zorica.dodevska@li.rs ISSN 2560-4961(online)

(C) 2018 IPMA Serbia

doi: 10.18485/epmj.2018.8.1.3 


\subsection{Real Reality (RR)}

Although there are different philosophical views and debates in terms of what the real world is (is our reality only illusion, and therefore virtual as any other?), in this paper we will use RR to represents the 'real' world that we live in. We can experience it with our five senses.

\subsection{Virtual Reality (VR)}

Opposite of RR, VR represents only virtual world that does not have any common with RR. It is totally artificial 3D computer- generated digital environment. The idea of VR has come from the game industry, but it becomes increasingly present in different industry fields. We cannot experience virtual world without using appropriate hardware and software.

\subsection{Augmented Reality (AR)}

$\mathrm{AR}$ is a combination of $\mathrm{RR}$ and computer graphics (Martin, 2017), that involves computer generated elements or virtual objects which appear as one or more layers over real environment (Porter, \& Heppelmann, 2017) in real-time. Some of the most known examples of $A R$ in everyday life are: AR "head-up display" (HUD) for vehicle navigation that shows us real paths (real user environment) and virtual helping navigation elements (Porter, \& Heppelmann, 2017), Pokémon Go mobile AR game, mobile apps for product visualization in real environment, etc.

\subsection{Augmented Virtuality (AV)}

$\mathrm{AV}$ adds real world components to virtual world, so it is more virtual than AR. Virtual environment is dominant in this case and represents a place where user interaction occurs.

\subsection{Mixed Reality (MR)}

There is no single interpretation of MR in the literature. MR could refer to:

- more complex or interactive mixture of realities where the boundaries of the real world are not obvious to user;

- different degree of reality-virtuality along the Milgram's Reality-Virtuality continuum (X-axis);

- all types of reality in the broader sense. It should be noted that there is a tendency to abandon the term MR in favour to AR.

\subsection{The other terms}

Some authors go a step further and introduce the second axis - the Mediality or Y-axis (for example, Mann, Furness, Yuan, Iorio, \& Wang, 2018). Mediality continuum is related to modified versions of reality achieved by changing reality through the media.

We can notice that there are various types of reality described in the literature, and there is a need for unification and standardization of terminology in this field. The term CrossReality (XR) is often used as an umbrella term (along with the term MR). In simple terms, XR represents some kind of exchange of information or media between real and virtual world (Coleman, 2009). Some authors call it Extended Reality, i.e. a combination of real and virtual world supported by humanmachine interactions.

\subsection{Usage of the terms in this paper}

The authors conducted quantitative analyses of articles at Google Scholar about the share of articles dealing with AR, VR, or MR in all articles, searching for the data in the last 30 years, and from the beginning 2018 to date: 01.01.2018 - 15.08.2018 (Figure 2). 


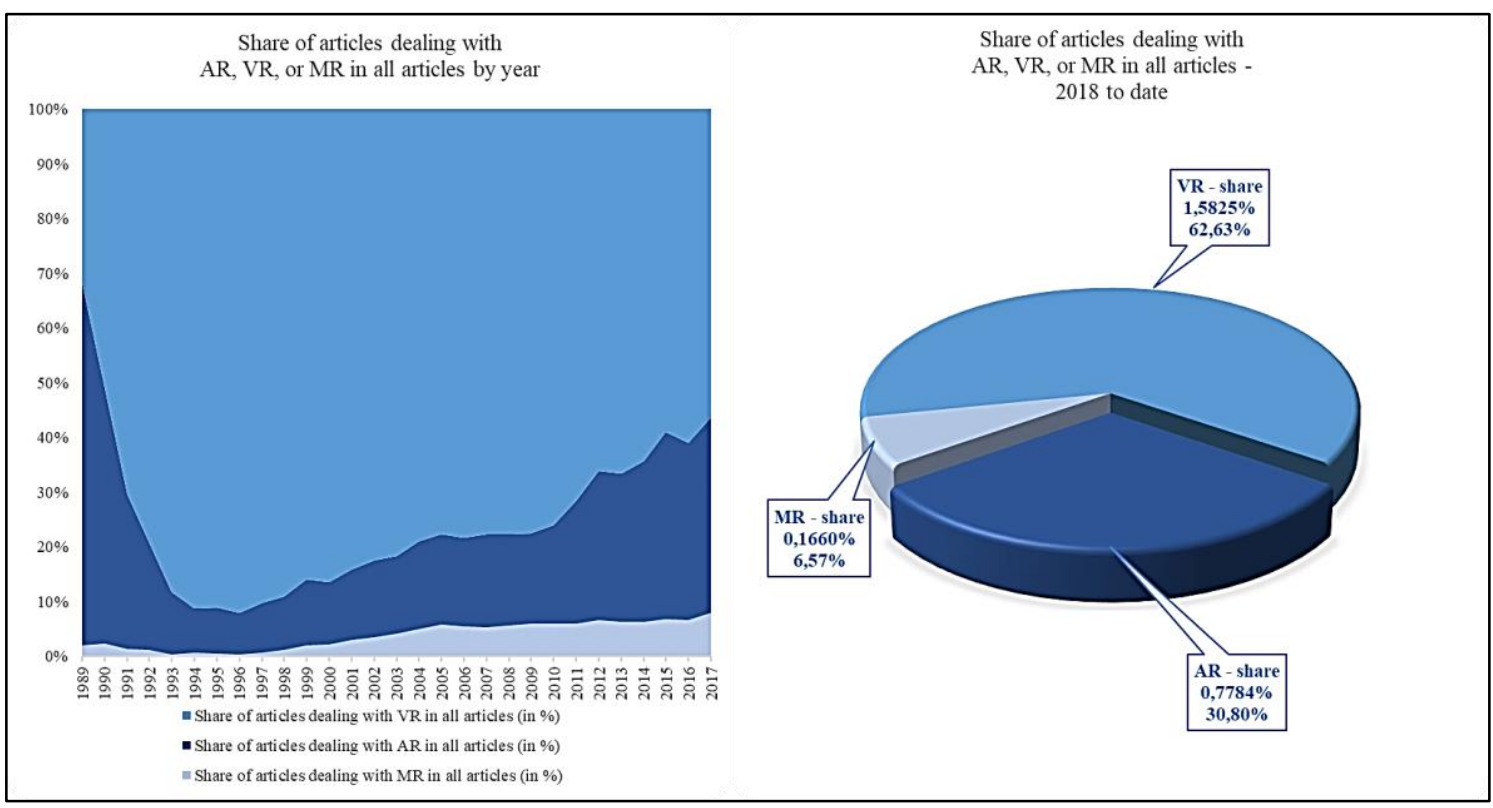

Figure 2: Share of articles dealing with AR, VR, or MR in all articles at Google Scholar (in the last 30 years, on the left side, and from the beginning 2018, to date: 01.01.2018 - 15.08.2018, on the right side)

As it is shown in Figure 2, AR and VR are dominant technology trends in this field, so the authors decided to focus on them in this paper. The other reasons for this decision are simplification of the terminology and adherence to the industry leading trends, as they were presented at the Google's I/O 2018. conference (please check Figure 3).

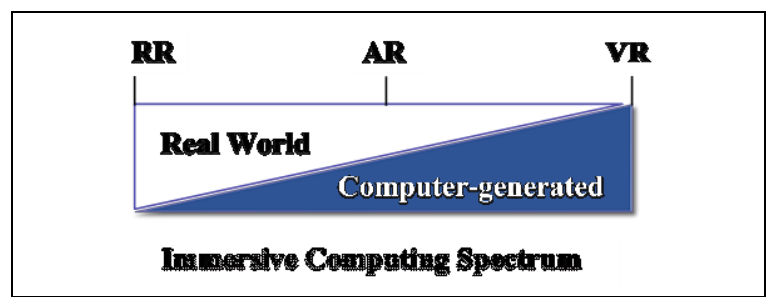

Figure 3: RR, AR, and VR (presented at Google's I/O 2018. conference)

Having in mind that there are differences between the terms AR and VR (please check Table 1), in this paper AR/VR will be used together to designate both technologies.

Table 1: Differences between AR and VR Augmented Reality Virtual Reality Combination of Totally artificial digital and real world. digital world.

$\begin{array}{ll}\text { User experience is } & \text { Complete sense of } \\ \text { partially immersed. } & \text { immersion. }\end{array}$

\begin{tabular}{|c|c|}
\hline $\begin{array}{l}\text { Camera-enabled } \\
\text { devices such } \\
\text { smartphone, tablet, or } \\
\text { smart glasses are } \\
\text { required. Desktop and } \\
\text { laptop devices are not } \\
\text { suitable because of its } \\
\text { fixed camera position, } \\
\text { unless an external } \\
\text { camera is used. }\end{array}$ & $\begin{array}{l}\text { Special hardware } \\
\text { equipment is } \\
\text { required } \\
\text { (Microsoft } \\
\text { HoloLens, HTC } \\
\text { Vive, Oculus Rift, } \\
\text { Google Daydream, } \\
\text { Google } \\
\text { Cardboard, etc). }\end{array}$ \\
\hline $\begin{array}{l}\text { Latest versions of } \\
\text { common operating } \\
\text { systems are good } \\
\text { enough (Android, } \\
\text { iOS, Windows). }\end{array}$ & $\begin{array}{l}\text { software is } \\
\text { d. }\end{array}$ \\
\hline $\begin{array}{l}\text { Initial costs can be } \\
\text { considerably lower } \\
\text { than for VR. }\end{array}$ & $\begin{array}{l}\text { Initial costs can be } \\
\text { considerably } \\
\text { higher than for } \\
\text { AR. }\end{array}$ \\
\hline
\end{tabular}

\section{WHERE DO AR/VR TECHNOLOGIES TAKE PLACE IN PM?}

There are inexhaustible opportunities for application of AR/VR in different fields and PM associated with them. Some examples are shown in Table 2. 
Table 2: Application of AR/VR in PM

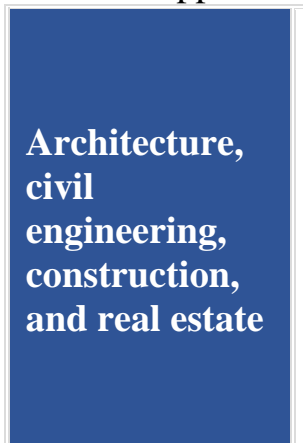

Instead of standard 2D format of drawings and renderings, investors and customers can now experience realistic impression of their future buildings, flats, business places, both from the outside and from the inside. Application of AR/VR technologies in these kinds of projects significantly reduces costs and time expenditure, improves design, and facilitates construction planning. Also, there is a research that synthesizes current VR/AR applications from the point of construction safety with the conclusion that AR/VR applications already achieved lot in that field, and there is more space for further improving their application in construction safety ( $\mathrm{Li}, \mathrm{Yi}$, Chi, Wang, \& Chan, 2018).

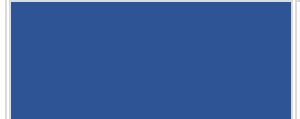

Many companies have recognized additional values for both marketers and customers. For instance, Ikea Place app helps customers in fast decisionMarketing and sales tablets. It analyses customer's room and puts furniture in adequate position. For wider use, there is a tool that promotes commercial sales - Amazon's app which lets to place items inside customer places using AR, to see how items will fit the space.

AR/VR technologies offer great opportunities and diversity in education (remote learning, interactive learning, 'real' lessons, etc). This also involves education of experts for PM, who should be both educated by using such technologies, and be educated to apply these technologies in their work.

There are many examples of AR/VR projects for general use in education, for example: SCARLET - Special Collections using Augmented Reality to Enhance Learning and Teaching (University of Manchester), cARe Creating Augmented Reality in Education (City, University of London), ARstudio - Australian research project (the University of Canberra, the Australian National University, and Macquarie University), NYC Media Lab prototyping projects (New York University, Columbia University, etc), AR-FOR-EU - Augmented Reality in Formal European University Education (several universities from UK, Norway, Germany and Russia). However, university curricula for education of the PM experts for AR/VR based project management appear rarely.

Besides university education, education in enterprises (e.g. trainings) and individual education (e.g. apps available on the Internet) are also applicable in this innovative field.

\section{'Visual'} industries

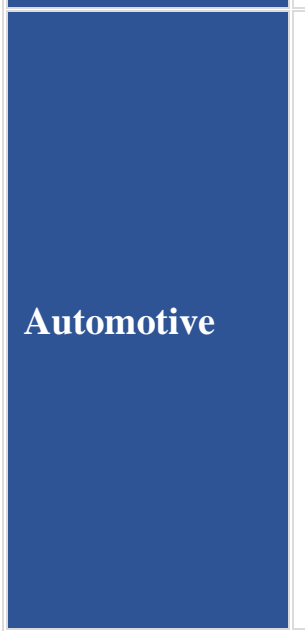

There are many examples of using AR/VR and related projects in this field: game industry, fashion industry, entertainment industry - cinema, film, travelling exhibition (e.g. landmarks, museums), etc.

AR/VR solutions are used for test drives, car elements testing, car dealership experience, etc. For example, Volkswagen adopts VR and AR solutions with belief that they help the company to successfully deal with increasing demands that automotive industry has been facing on. The company systematically engage employees to use VR and AR solutions for training and collaboration to empower their brands and business departments. They developed smart infrastructure that enables training, collaboration and service integration worldwide. Employees and whole teams learn within an interactive 3D space. This solution increases training efficiency, reduces learning time and travel costs, and helps transfer of relevant knowledge in solving practical tasks. In trainings, they use scenarios that involve workers from different brands and locations. During the training, the workers can discuss different topics with expert trainers and developers. It makes possible to create content faster and more efficient. 


\begin{tabular}{|c|c|}
\hline Manufacturing & $\begin{array}{l}\text { In complex manufacturing processes AR is useful in delivering the right } \\
\text { information at the right moment to factory workers on assembly lines } \\
\text { (Porter, \& Heppelmann, 2017). This is efficient in reducing errors, reducing } \\
\text { costs, time saving, and productivity improving (Porter, \& Heppelmann, } \\
\text { 2017). Any operator in Industry } 4.0 \text { with the help of AR could be a smart } \\
\text { operator soon, while simulation and optimization will be supported by VR } \\
\text { technologies (World Economic Forum, \& Kearney, 2017). }\end{array}$ \\
\hline Healthcare & $\begin{array}{l}\text { Training of surgeons is one of the most important field of application of the } \\
\text { AR/VR technologies in healthcare. There are examples of usage AR/VR } \\
\text { technology in triage and urgent care, for example Red Cross Triage AR } \\
\text { application using Google Glasses. }\end{array}$ \\
\hline Defence & $\begin{array}{l}\text { TARGET (Training Augmented Reality Generalized Environment Toolkit) } \\
\text { is European project which started } 2015 \text { and planned to end in 2018. It is } \\
\text { funded by the EU Horizon } 2020 \text { (LIST website). The project develops AR } \\
\text { and VR solutions for training of the security critical agents (for example, } \\
\text { policeman, fireman, emergency medical staff, anti-terrorist units, etc). } \\
\text { The project uses different approaches allowing remote connection of AR } \\
\text { and VR systems to geolocation and other tools, involving 3D modelling, } \\
\text { photogrammetry, drones and many other state-of-the-art technologies. It } \\
\text { creates new-made mixed reality environment where trainings are provided } \\
\text { in extreme under-pressured security situations. Improving and optimization } \\
\text { of training is the aim of the project, which has several key impacts, including } \\
\text { developing easy customizable and low-cost advanced training } \\
\text { environments. } \\
\text { The current phase of the project has been successfully finishing. The project } \\
\text { continues to unfold, harvesting already achieved results. }\end{array}$ \\
\hline $\begin{array}{l}\text { Service } \\
\text { support }\end{array}$ & $\begin{array}{l}\text { Remote technical and expert support, visualized instructions, remote } \\
\text { repairing, knowledge exchange, etc. Thanks to AR/VR technologies, } \\
\text { maintaining and repairing at remote locations is possible. For example, } \\
\text { industrial giant ABB uses AR to maintain and repair equipment at remote } \\
\text { locations which they found particularly useful in dangerous and complex } \\
\text { remote procedures (Harvard Business Review Staff, 2017). }\end{array}$ \\
\hline
\end{tabular}

Implementation of AR/VR technologies in PM is multiple:

- AR/VR as a topic of project. Training of surgeons, pilots or special antiterrorist forces using AR/VR technologies are some of many examples.

- Project may refer to the development of products that contain some type of AR/VR. For instance, a project in commercial airline traffic - production of HUD which shows superposition of projected landing route on the runway (example: Aero Glass).

- Remote collaboration and PM based on AR/VR technologies. There are many examples of remote collaboration in PM. For example, Unity presents such projects in automotive for testing cars (Audi), training (Volkswagen), virtual showrooms (Cadillac), etc.
- AR/VR-based projects for education. There are a lot of such projects in educational field, like Google Expeditions where ,teachers can take students on immersive journeys both with AR and VR" (retrieved from Google Expeditions website).

- Development projects of complete AR/VR-based platforms for real-time remote collaboration, which include hardware, software, knowledge exchange, and real-time remote assistance in many different types of projects (for example, Vuforia Chalk).

- Virtual PM and e-PM. Mihić, Petrović, \& Obradović, (2012) stress the importance of communication and collaboration in virtual project teams. AR/VR technologies naturally support these processes. Since, resources of virtual projects and e-projects are 
spatially and temporally dislocated, virtual PM and e-PM demand ICT support. Software solutions for collaboration and distributed PM take over the key role. Hence, virtual PM and e-PM are suitable for the application of AR/VR technologies.

- $A R / V R$ can be used in different project management phases, in the abovementioned examples.

\section{BENEFITS AND OBSTACLES OF USING AR/VR IN PM}

\subsection{Benefits}

There are several important benefits of using AR/VR in PM. They are useful for decision making problems in complex projects. This is particularly important for fields where prompt and accurate reactions are extremely important (like life-saving situations or some security related projects). In addition, with the help of $\mathrm{AR} / \mathrm{VR}$, easier and much faster understanding of large amount of data is possible.

Real-time remote collaboration reduces travel costs, facilitates logistics, reduces time-torepair. Generally, usage of AR/VR technologies in PM improves efficiency (time and resource saving) and increases productivity. Also, they enable much efficient monitoring of machines and processes.

The validation process could be moved at the beginning of the project in many cases, because visualization of future products now can be presented to customers in the development phase. Also, iterations and number of attempts and testing in development phase no longer need to be expensive and strictly limited, which is encouraging for innovative activities.

Commercialization of projects could be significantly improved by providing rich experience to end-users (interactive experience, in-store customer experience, personalized customer experience, etc).

\subsection{Obstacles}

One of the main discouraging factors for AR/VR implementation in PM are inevitable hardware and software requirements. This implies some initial costs which can be significant, especially in the cases of smaller projects.

Some of the hardware requirements for AR/VR implementation in PM could be headsets or special glasses, such as Microsoft HoloLens, Oculus Rift, Google Daydream, Google Cardboard, and many others. For professional applications in PM, hardware devices must be supported by adequate software, which often requires significant material investments. In addition, once when a platform is chosen, it is not quite simple to change it for future projects. These costs could be discouraging, particularly because the complex remote collaborated projects, handling with large amount of data, inevitable require specialised hardware and software. Although, there are still very useful and highly efficient tools for AR/VR in PM that require only software, and work with common smartphones and tablet devices (the "common" here means the high class and the latest devices - for example, mobile devices are currently required to have newest operating system and highest quality camera and processor). However, the field of application of such technologies for the professionals is not as broad as for the technology that uses completely specialised hardware and software (like Microsoft HoloLens and similar).

\section{FUTURE TRENDS AND SWOT ANALYSIS}

Since first prototypes of the pioneering AR/VR technology were introduced, governments, industries, and technology giants have recognised their potential. They invest large resources in AR/VR projects. For PM, this means both that it should be counted on raise in requests for managing such projects, and that PM education must provide experts who can efficiently deal with such projects.

AR/VR are currently among dominate technology and business trends. AR markets are estimated to grow to $\$ 120$ billion by 2020 , i.e. $\$ 150$ billion of both $A R$ and VR in total sum (GutCheck, 2018). Despite the fact that AR projects are still in the process of proving in many companies, $48 \%$ of companies surveyed by PTC in 2017, are planning transition to production within one year, and 26\% within two years (Campbell, Kelly, Jung, \& Lang, 2017). 
Because AR/VR technologies represent continually growing area where new ideas every day reveal, a SWOT analysis is given in this paper. For more information please check the Figure 4 where strengths, weakness, opportunities, and threats of implementation of $\mathrm{AR} / \mathrm{VR}$ technologies in PM are listed as the conclusion of the previous research of literature and current novelties in this field.
Strengths:

-Increase in competitive ability.

-Increase in efficiency (reduce time and costs) and productivity (reduce errors, facilitate work processes).

-Enable fast remote support for repairing systems weaknesses.

-Enable fast and remote collaboration.

-Involve innovation support.

-Facilitate understanding of large amounts of data.

- Facilitate decision making problems solving (visualization of information).

-Facilitate monitoring of projects.

- Reduce project validation risks.

\section{Weaknesses}

- Initial costs for adopting could be significant.

-Adopting AR/VR tecnologies could require time for administration procedures.

- Once when a platform is chosen, it could not be quite simple to change it for future projects.

- Possible fast device aging because of the rapid technology development.

-Lack of PM experts who mastered these technologies.

\section{SWOT analysis of implementation of AR/VR technologies in PM}

Opportunities
• Possibility of usage in different types of
projects.

Figure 4: SWOT analysis of implementation of AR/VR technologies in PM 


\section{CONCLUSIONS}

PM using AR/VR technologies is not something to come - it is here. AR and VR technologies bring business transformation, provide better knowledge transfer, help businesses to drive innovation (to test various kinds of ideas), enhance productivity and solutions, increase competitive ability, increase efficiency, tend to equal operational excellence of human and machines, include real-time remote collaboration, and in some fields include immeasurable benefits like much better chances for saving human lives. Despite some identified challenges, these are some reasons why PM will broadly accept those technologies, which is confirmed by forecasts of the future trends. It is expected that development of PM practice will also affect body of knowledge, future researches, and the education of PM experts.

\section{REFERENCES}

Campbell, M., Kelly, S., Jung, R., \& Lang, J. (2017). The State of Industrial Augmented Reality 2017. PTC, White Paper.

Coleman, B. (2009). Using sensor inputs to affect virtual and real environments. IEEE Pervasive Computing 8 (3), pp. 16-23, doi: 10.1109/MPRV.2009.60

Google Expeditions website:

https://edu.google.com/expeditions/\#abo ut (accessed on 21st July 2018).

GutCheck. (2018). Consumer Perceptions of Augmented Reality. Exploratory Research Group, 40 pages.

Harvard Business Review Staff. (2017). A Manager's Guide to Augmented Reality. Article collection, November-December 2017.

Kugler, L. (2017). Why Virtual Reality Will Transform a Workplace Near You.
Communications of the ACM, 60 (8), pp. 15-17, doi: https://doi.org/10.1145/3105444

Li, X., Yi, W., Chi, H. L., Wang, X., \& Chan, A. P. C. (2018). Automation in Construction 86 (2018), pp. 150-162, doi: https://doi.org/10.1016/j.autcon.2017.11. $\underline{003}$

LIST website - Luxembourg Institute of Science and Technology, https://www.list.lu/ (accessed on 23st July 2018).

Mann, S., Furness, T., Yuan, Y., Iorio, J., \& Wang, Z. (2018). All Reality: Virtual, Augmented, Mixed (X), Mediated $(X, Y)$, and Multimediated Reality. 14 pages, arXiv:1804.08386

Martin, B. S. (2017). Virtual Reality. Norwood House Press: Chicago, Illinois, US.

Mihić, M., Petrović, D., \& Obradović, V. (2012). Analysis of Communication Aspects to Virtual Project Management. In Proceedings of the XIII International Symposium SymOrg 2012: Innovative Management and Business Performance, SymOrg 2012, Zlatibor, Serbia, June 5-9, 2012; Levi-Jakšić, M.; BarjaktarovićRakočević, S. (Ed.), 1517 - 1525.

Milgram, P., Takemura, H., Utsumi, A., \& Kishino, F. (1994). Augmented Reality: A class of displays on the reality-virtuality continuum. Telemanipulator and Telepresence Technologies.

Porter, M. E., \& Heppelmann, J. E. (2017). Why Every Organization Needs an Augmented Reality Strategy. Harvard Business Review, 95 (6), pp. 46-57.

World Economic Forum, in collaboration with Kearney, A. T. (2017). Technology and Innovation for the Future of Production: Accelerating Value Creation, White Paper. 